\title{
Selective laser sintering of glass-ceramic bonds using a defocused Nd:YAG laser
}

\author{
K. Murawski, K. Aristovich, H.T. Lancashire* \\ Department of Medical Physics and Biomedical Engineering, \\ University College London, \\ Gower Street, London, WC1E 6BT, UK \\ *Email: h.lancashire@ucl.ac.uk
}

\begin{abstract}
Protecting miniature implantable electronics may require $\mathrm{mm}$ scale hermetic packages. Glass-ceramic bonding by selective laser sintering of glass sealing paste using a defocused Nd:YAG laser is presented. Glass sealing paste (FX11-036, Ferro) is screen printed onto alumina ceramic, clamped in contact with borosilicate glass, and laser treated while heating to $250^{\circ} \mathrm{C}$. With the addition of defocusing and a heat source the glass paste reflowed and wetted both the alumina and coverslip surfaces, with an optimal effect between $10 \mathrm{~mm}$ and $15 \mathrm{~mm}$ defocusing. This method is promising to create electrically non-conductive hermetic seals at the mm scale.
\end{abstract}

Key words

Nd:YAG laser, Glass, Ceramic, Sealing.

\section{Introduction}

Rapid prototyping methods for implantable devices are essential to take bioelectronics from the benchtop to the clinic. Long-term implantable devices may require hermetically sealed packages to protect active components $[1]$.

Metal packages, or conductive seal rings are problematic for integrating inductively coupled power-data links inside packages [2],[3]. Therefore, non-conductive hermetic seals are sought. One such approach is using a sealing glass material in place of a solder seal ring. Glass seals have been achieved by furnace-bonding samples; however, this also heats active components in the package to temperatures in the range of $500{ }^{\circ} \mathrm{C}$ [2],[4].

Glass-glass welding using laser-targeted heating to bond surface-applied glass-frit paste is promising to create rapid miniature seals within only localized heating as the seal. Current research primarily concerns continuous wave lasers, and ultrashort picosecond and femtosecond pulsed lasers [5],[6]. Using femtosecond lasers direct glass-glass bonding can be achieved without a glass-frit paste layer [7],[8]. Limited research has used nanosecond lasers to weld glasses, requiring custom interlayers such as Ti films, perhaps due to the highly ablative effect [9],[10].

Laser sintered glass-ceramic seals will prove valuable for hermetic packaging. Thick film ceramic hybrids are a widespread process for creating durable active devices, and are sufficiently hermetic for implantable devices [1]. Glassfrit pastes can be integrated into the thick film printing process to form seal rings, while a glass package lid allows for selective laser bonding. In this work laser welding of glass to ceramic layers is achieved using a glass sealing paste interlayer and an $\mathrm{Nd}$ :YAG nanosecond laser.

\section{Methods}

\section{A. Thick-Film Sample Preparation}

Glass sealing paste (FX11-036, Ferro) was screen printed onto $550 \mu \mathrm{m}$ thick, 1 " square, $96 \%$ Alumina ceramic samples (CeramTec) using a 325 mesh, $20 \mu \mathrm{m}$ emulsion thickness, screen, and a DEK1202 screen printer. For the present study paste was printed uniformly across the entire ceramic substrate surface; for design specific seal rings paste can be applied in any screen-printable shape. Printed samples were levelled at room temperature for 5 minutes and dried in an air circulating oven at $125^{\circ} \mathrm{C}$ for 10 minutes. Dried samples were fired in a DEK 840 belt furnace, with a peak temperature of $450^{\circ} \mathrm{C}$ maintained for 20 minutes, a ramp rate was chosen appropriate to the paste binder burnout cycle. 


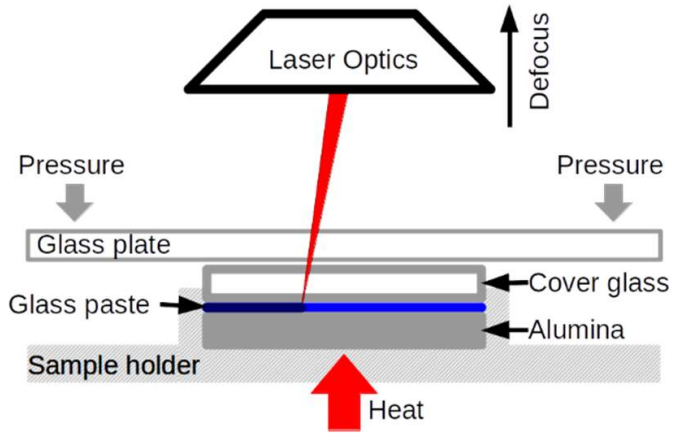

Fig. 1: The experimental setup showing: laser optics with optional defocusing; optional glass clamping plate applying pressure; optional cover glass for bonding; glass paste (prefired); alumina substrate; sample holder; and optional heating to $250^{\circ} \mathrm{C}$. Optional components were included for some experiments.

\section{B. Experimental Setup}

The experimental setup is shown in Fig. 1. A Laservall Violino-2 Nd:YAG nanosecond pulsed laser with $1064 \mathrm{~nm}$ wavelength, delivering a maximum of $10 \mathrm{~W}$ average power was used. Preliminary experiments identified appropriate ranges of pulse frequency and scan speed. Initial experiments were carried out with only glass paste coated alumina samples to determine parameters for subsequent steps.

\section{Laser Processing}

To create a glass-glass-ceramic interface, borosilicate glass coverslips (Thermo Fisher) were clamped to the fired glass paste surface in a custom jig. A pressure of at least $2.3 \mathrm{kPa}$ was applied between the coverslip and the glass paste using weights, with a glass plate used to distribute the pressure evenly. The effects of sample heating and laser defocusing were investigated. Samples were heated on a hotplate to $250^{\circ} \mathrm{C}$ before laser treatment. The laser beam was defocused by increasing the distance between the laser optics and the glass paste surface. The system focal distance was $100 \mathrm{~mm}$, and this was increased in $1 \mathrm{~mm}$ increments to a total distance of $120 \mathrm{~mm}$ ( $20 \mathrm{~mm}$ defocus). The effect of laser power (\% of $10 \mathrm{~W}$ average) was investigated at $10 \mathrm{kHz}$ pulse frequency, $12 \mathrm{~ns}$ pulse width, for in-focus and defocused samples. For all experiments the laser path was swept at $23 \mathrm{~mm} / \mathrm{s}$ in a spiral to form a $1 \mathrm{~mm} \times 1 \mathrm{~mm}$ bond area, or swept sinusoidally to form a $1 \mathrm{~mm}$ wide seal ring, the $1 \mathrm{~mm}^{2}$ path took 8 minutes to cover the entire area.

\section{Sample Analysis}

Following laser treatment glass pastes which underwent reflow were observed to take on a "glassy" quality. This was characterised by a more reflective and varied surface, with an increase in bright spots on light micrographs. To quantify
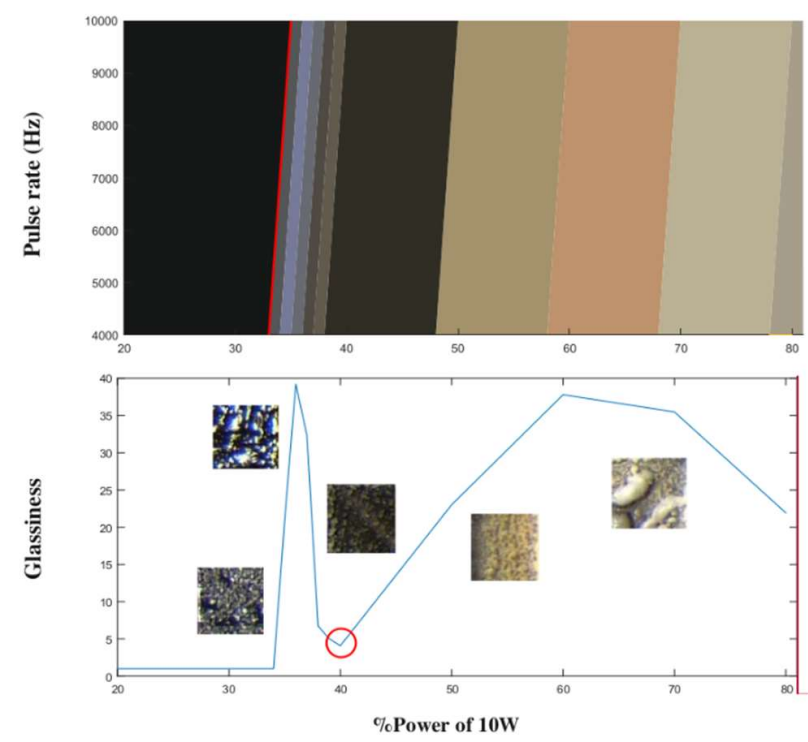

Fig. 2: Observed colour change (above) and glassiness values for $10 \mathrm{kHz}$ pulse frequency (below) following laser treatment of FX11-036 glass paste on alumina ceramic. A clear peak in glassiness is present at $37 \%$ power with no effect below approximately $35 \%$ power, and ablation and material damage occurring above $40 \%$ power. Inset micrographs show the surface after treatment.

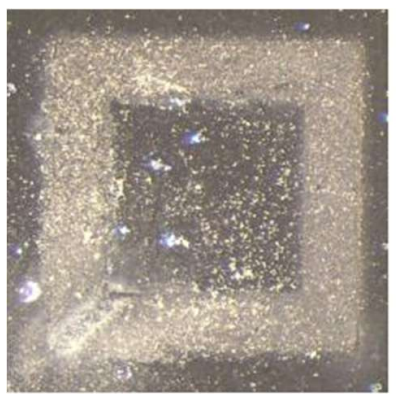

(a)

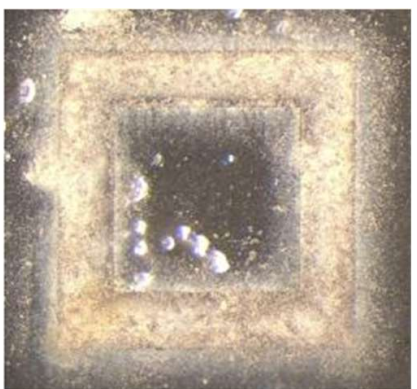

(b)
Fig. 3: FX11-036 glass paste samples after laser treatment with a borosilicate glass cover slip in place. Laser focused at the surface of the glass paste. (a), 35\% power; (b), $40 \%$ power. No bond is formed and an etched, powdery surface forms on the coverslip in the same region.

this, we developed the "glassiness" parameter. ImageJ (FIJI ImageJ v1.52p) was used to measure the 8-bit RGB values from reflection light micrographs of treated and untreated samples. "Glassiness" was sample mean RGB value multiplied by sample RGB standard deviation. This approach maximised glassiness for reflective, varied images. Glassiness was also observed to increase where ablation exposed the underlying, white, alumina surface. 


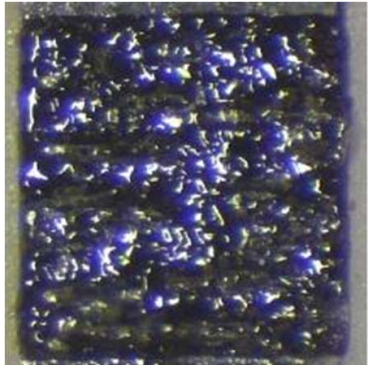

(a)

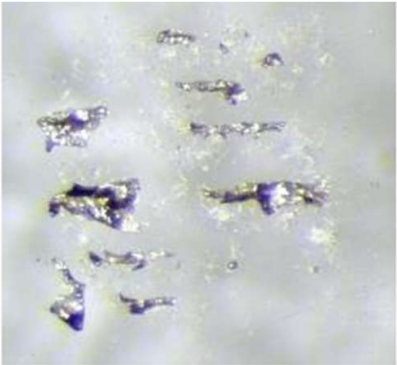

(b)
Fig. 4: FX11-036 glass paste sample (a) after laser treatment at $35 \%$ power with a borosilicate glass cover slip (b) in place. Laser focused at the surface of the glass paste. The sample was heated to $250^{\circ} \mathrm{C}$ using a hot plate before laser treatment. A weak, patchy, bond is formed, and the coverslip is damaged and cracked. $1 \mathrm{~mm}^{2}$ area treated.

\section{Results}

\section{E. Without Defocusing}

First investigations showed the effect of focused laser treatment on glass paste for a range of laser powers and pulse frequencies (Fig. 2). The screen-printed glass paste took on a glassy, reflective appearance following laser treatment at between $35 \%$ and $40 \%$ power. At higher powers ( $>40 \%)$ the glass paste was ablated, damaging the paste and exposing the underlying ceramic. Without heating the substrate no bond was formed to a glass cover slip (Fig. 3), the cover slip was damaged by any ablation which occurred to the underlying sample leaving a roughened opaque surface. When samples were heated to $250^{\circ} \mathrm{C}$ before laser treatment weak patchy bonds to the cover slip were observed (Fig. 4), cracks were visible in the coverslips and bonds were easily delaminated during handling, or following reheating to $250^{\circ} \mathrm{C}$.

\section{F. With Defocusing}

The effect of defocusing the laser was investigated on samples heated to $250^{\circ} \mathrm{C}$. In the absence of a cover slip increasing defocusing increased the extent to which the glass paste reflowed (Fig. 5). Between $8 \mathrm{~mm}$ and $15 \mathrm{~mm}$ defocus the glass paste completely reflowed exposing the underlying ceramic. When a cover slip was applied stable bonds were observed at above $60 \%$ power, with the affected area increasing with laser power (Fig. 6). Bonds extended up to $400 \mu \mathrm{m}$ outside the $1 \mathrm{~mm}^{2}$ treated area as a ring of remelted glass paste.

\section{Discussion and Conclusion}

We present the development of a method to create mm scale glass-ceramic seals. The method uses a low temperature

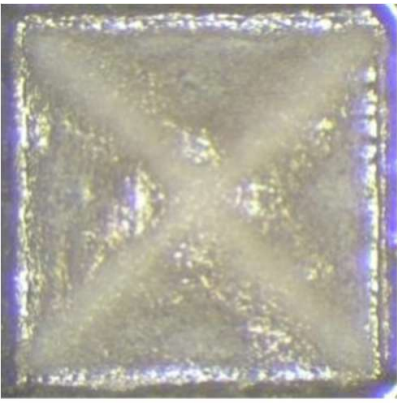

(a)

(c)

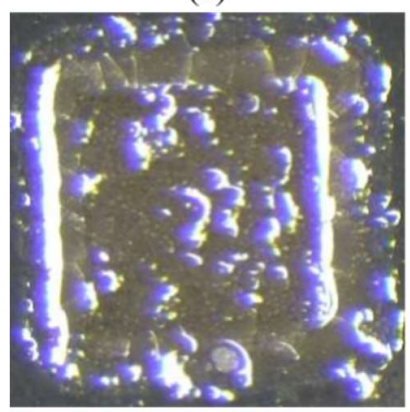

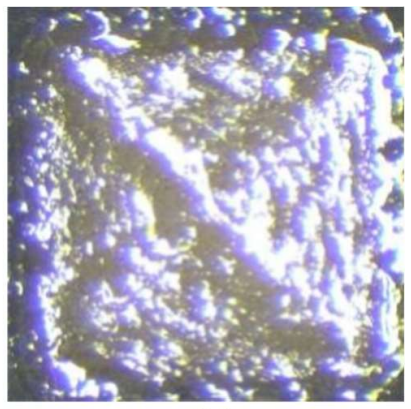

(b)

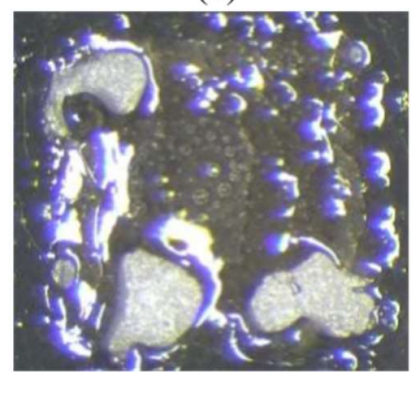

(d)

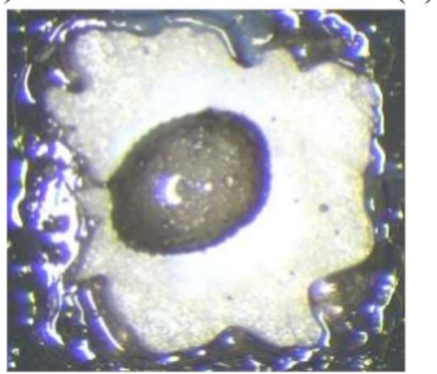

(e)

Fig. 5: The effect of laser defocusing from 0 to $+15 \mathrm{~mm}$ on glass paste. Representative samples show the effect in the following range of defocus heights (all in $\mathrm{mm}$ ). (a), $0 \leq \mathrm{x}<$ 1.5; (b), $1.5 \leq \mathrm{x}<4$; (c), $4 \leq \mathrm{x}<8$; (d), $8 \leq \mathrm{x}<12$; (e), $12 \leq$ $\mathrm{x} \leq 15$. Increasing defocus moves from ablation (a), through a glassy region $(b, c)$, to glass reflowing $(\mathrm{d}, \mathrm{e})$.

sealing glass layer, uniform substrate heating to $250^{\circ} \mathrm{C}$, and localised substrate heating with a defocused Nd:YAG laser. We developed this process using uniformly screen-printed glass surfaces, for micropackaging seal rings can be created in custom dimensions using the same screen-printing process used to create the ceramic hybrids to be packaged. Our results suggest $100 \mu \mathrm{m}$ scale bonds can be achieved, making $\mathrm{mm}$ scale packages possible.

Results show that process parameters are key to achieving a bond, while the presented methods are applicable to Ferro FX-11-036 sealing glass pastes, we predict that different parameters will be required for alternative pastes. We have tested a range of alternative glass pastes and observed that similar ablation occurs at greater than $4 \mathrm{~W}$ average power $(40 \%)$ using a focused laser, this process window is similarly 


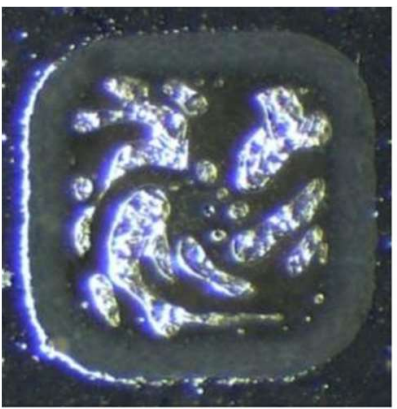

(a)

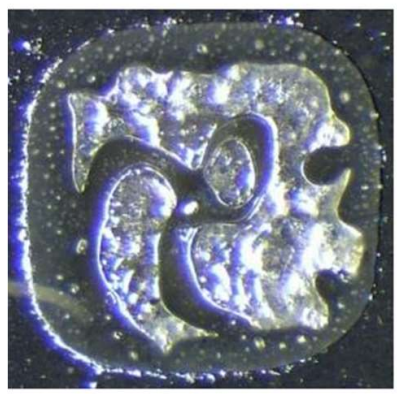

(c)

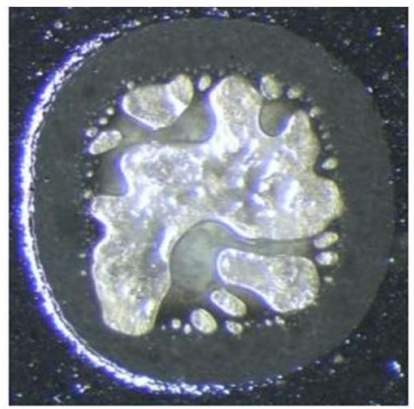

(b)

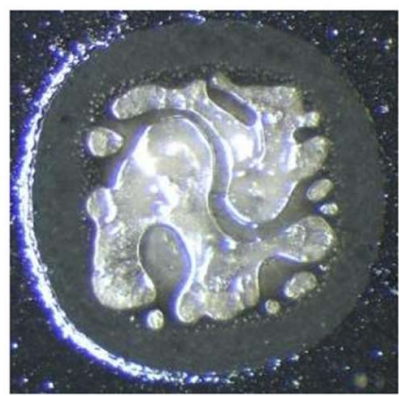

(d)
Fig. 6: Light micrographs of bonded ceramic - FX-11-036 borosilicate glass samples. Samples laser treated on a hot plate at $250^{\circ} \mathrm{C}$ with: (a), $11 \mathrm{~mm}$ defocus, $60 \%$ power; (b), 11 mm defocus, $100 \%$ power; (c), $13 \mathrm{~mm}$ defocus, $60 \%$ power; (d), $13 \mathrm{~mm}$ defocus, $100 \%$ power. Laser treatment is applied to a central $1 \mathrm{~mm}^{2}$ area, a heat affected zone is clear, which expands from $200 \mu \mathrm{m}$ width to $350 \mu \mathrm{m}$ width with increasing power. Bubbles are due to laser treating the entire area and the paste covering the entire alumina surface.

narrow for other pastes.

For glass-ceramic sealing using an Nd:YAG laser we predict that substrate preheating and laser defocusing are key steps to achieving a bond. Laser defocusing helps avoid the ablation associated with the small focused beam diameter (30 $\mu \mathrm{m}$ for the present system) [11]. Defocusing reduces the spatial accuracy of this method, and we hypothesise that this effect combined with heat expansion and gas evolution caused the bubbles and expanded bond area observed in Fig. 6. The present samples comprised an alumina substrate completely coated in glass paste, and a solid area was laser treated. When treating a seal ring, adjacent space will be available for expansion, and gas evolution; therefore, we predict the effects observed in Fig. 6 will be reduced.

Heating the entire package to $250^{\circ} \mathrm{C}$ will cause solder joints within the package to reflow, while wire bonded structures will be aged by the heating, the effect of this process on active and passive components must be investigated. The pre-heating temperature of $250^{\circ} \mathrm{C}$ was not optimised in this work, lower temperatures may result in acceptable bonding while maintaining solder joints below their reflow point. The package heating will help reduce temperature shocks which would occur if heating from room temperature to reflow temperature in a single step, in the present study the thermal expansion coefficient of the glass paste and the alumina were matched, however this was not matched to the glass coverslip. These mismatches may result in stress concentration on cooling, and is a possible cause of the cracking and delamination observed in Fig. 4.

In the present study a $10 \mathrm{kHz}$ pulse frequency was used, in contrast to $20 \mathrm{kHz}$ as in [9]. We observed visually similar results to [9] when using a $100 \mathrm{kHz}$ pulse frequency without defocusing. Samples treated at high frequency exhibited the same cracking and fragility present in Fig. 4.

Although short in comparison to a complete furnace cycle, the 8 minute process time is a limitation of the present work. This will scale linearly with total bond area, rather than working as a batch process for furnace-bonding. Further optimization may reduce the process time; however, this method may only remain suitable for small sample sizes and small production runs.

The present samples are sealed in air. For hermetic encapsulation sealing under vacuum or in an inert atmosphere is expected to change the required parameters. Vacuum chambers have been shown to dramatically reduce the laser power required to reach the peak temperatures required for glass reflow [12].

The seal dimensions achieved suggest that $100 \mu \mathrm{m}$ to $1 \mathrm{~mm}$ scale bonds will be possible, larger than present state-of-theart chip scale packaging, but comparable with solder seals used for hybrid ceramic packaging. Avoiding a conductive seal ring or package will reduce losses for implant wireless receiver coils on or inside hermetic packages [2]. To develop this process for use in a medical device we are investigating the strength and hermeticity of the bonds, alternative commercial glass sealing pastes, possible glass paste dissolution in body fluids, and integrating conductive metal feedthroughs across the glass-ceramic seal.

\section{Acknowledgment}

The authors acknowledge technical assistance from Ms T. Grego and access to equipment from $\mathrm{Dr} A$. Vanhoestenberghe and Prof N. Donaldson.

\section{References}

[1] A. Vanhoestenberghe, and N. Donaldson, "Corrosion of silicon integrated circuits and lifetime predictions in implantable electronic devices," Journal of Neural Engineering, vol. 10(3), 2013, p. 031002 , doi: 10.1088/1741-2560/10/3/031002.

[2] J. Ordonez, P. Dautel, M. Schuettler and T. Stieglitz, "Hermetic glass soldered micro-packages for a vision prosthesis," in Annual International Conference of the IEEE Engineering in Medicine and Biology Society, 2012, pp. 2784-2787, doi: 10.1109/EMBC.2012.6346542. 
[3] V. Sivaji, D. Grasse, S. Hays, J. Bucksot, R. Saini, M. Kilgard and R. Rennaker, "ReStore: A wireless peripheral nerve stimulation system," Journal of Neuroscience Methods, vol. 320, 2019, pp. 26-36.

[4] Z. Sun, D. Pan, J. Wei and C. K. Wong, "Ceramics bonding using solder glass frit," Journal of Electronic Materials, vol. 33, 2004, pp. $1516-1523$.

[5] K. Cvecek, S. Dehmel, I. Miyamoto and M. Schmidt, "A review on glass welding by ultra-short laser pulses," International Journal of Extreme Manufacturing, vol. 1(4), 2019, p. 042001, doi: 10.1088/2631-7990/ab55f6.

[6] I. Miyamoto, "Laser welding of glass," in Handbook of Laser Welding Technologies, S. Katayama, Ed. Woodhead Publishing, 2013, pp. 301-331, doi: 10.1007/BF0236853810.1007/BF02368538

[7] W. Watanabe, S. Onda, T. Tamaki and K. Itoh, "Direct joining of glass substrates by $1 \mathrm{kHz}$ femtosecond laser pulses," Applied Physics B: Lasers and Optics, vol. 87, 2007, pp. 85-89.

[8] S. Richter, S. Döring, A. Tünnermann and S. Nolte, "Bonding of glass with femtosecond laser pulses at high repetition rates," Applied Physics A. Materials Science \& Processing, vol. 103, 2011, pp. 257261.

[9] A. de Pablos-Martín and T, Höche, "Laser welding of glasses using a nanosecond pulsed Nd:YAG laser," Optics and Lasers in Engineering, vol. 90, 2017, pp. 1-9, doi: 10.1016/j.optlaseng.2016.09.009.

[10] J. F. Li, Y. H. Sun, D. W. Ding, W. H. Wang and H.Y. Bai, "Nanosecond-pulsed laser welding of metallic glass," Journal of NonCrystalline Solids, 2020, vol. 537, p. 120016, doi: 10.1016/j.jnoncrysol.2020.120016.

[11] A. Slocombe and L. Li, "Selective laser sintering of $\mathrm{TiC}-\mathrm{Al} 2 \mathrm{O} 3$ composite with self-propagating high-temperature synthesis," Journal of Materials Processing Technology, vol. 118, no. 1, 2001, pp. 173178, doi: 10.1016/S0924-0136(01)00905-0.

[12] N. Lorenz, S. Millar, M. Desmulliez and D. P. Hand, "Hermetic glass frit packaging in air and vacuum with localized laser joining," Journal of Micromechanics and Microengineering, vol. 21, 2011, p. 045039. 